\title{
Introduction: The violence of development
}

\author{
SMITU KOTHARI AND \\ WENDY HARCOURT
}

This special issue of Development takes a fresh look at the contentious and complex relationship between development and violence. The focus of the issue is deliberately not on development institutions, development aid or those 'doing development', but rather on development's reordering of society itself and the multiple kinds of violence that are a consequence of this reordering. What are critically examined are the processes of economic, political and social transformation/modernization carried out in the name of development. The issue also explores the changes in the conceptual and political map of transnational developmental relations, closely linked to the aftermath of post-September 11, 2001.

To some readers, this journal issue may seem a departure from the conventional understanding and use of what constitutes violence, but this is deliberately so. The authors, writing on communities' experiences in Columbia, Europe, India, Mexico, Pakistan, Palestine, Peru, Sri Lanka, Tanzania, Thailand, USA and Zimbabwe, ask questions about violence from the perspective of the increasingly vocal and visible voices of the majority of the world's men and women. These voices are compelling us to embrace a more comprehensive understanding of development-induced violence.

In illuminating the contentious link between development and violence, we are deliberately posing the question of whose vantage point counts. Is it possible to give primacy to the perspective of those excluded and victimized by development? How do forest dwellers, traditional fisher people, women and men eking out a living in urban slums, tribal and indigenous communities, contract workers, domestic workers far from home, displaced and migrant people, sex workers, orphans and refugees understand development given the violence of their everyday exclusion, exploitation, discrimination and marginalization?

Difficult as these questions may seem, as the articles in this issue attest, it is not just stories of victimization and conflict that are presented here, but the resistance these processes have engendered as well as the celebration of the multiple cultural realities that exist within and alongside development. This plurality must be noted and celebrated. Men and women at the community level, in the face of grave difficulty and frequently against great odds, and often supported by associative links beyond the local, are increasingly seeking to intervene constructively in their own conditions. They are finding ways to govern themselves, participating and seeking to redefine the contentious process of democracy, resisting and challenging the threats to their livelihoods 
and carving out innovative ways to shape positively their own lives. They are creating new structures to enable their own livelihoods, searching out different ways to relate to each other and to other communities, including the state. Many are creatively using the possibilities that the electronic and digital options have opened up to communicate within and beyond national boundaries. What remains an area of critical neglect, however, is how these processes are challenging and altering cultural traditions, class, caste and gender divides. And what is clear is the magnitude of violence faced by hundreds of millions of people victimized by development.

Difficult as it is to generalize the complex levels of violence in the development process, it is becoming evident that the victims of this violence are not just those who exist below what economists label 'the poverty line'. We can clearly identify various forms of violence that threaten life in all its plurality and diversity across the world.

First, violence is inbuilt in the continuing processes of industrialization and urbanization as they destroy livelihoods in addition to neglecting rural areas in favour of centralized urban industrial development. Further, planned development continues to displace people at an escalating pace, as in India where half a million people are annually displaced from their sources of sustenance and meaning. The grave physiological and psychological impacts that displaced people experience are well documented but little has been done to address this massive social and cultural violence done in the name of development to millions of people every year. These processes are compounded by economic globalization based on the global extraction of resources and cheap labour, on global trade blocs and on new zones of privilege, which, in numerous cases, continue historical trends of colonial exploitation, reinforce or create new political, economic and cultural hierarchies, exacerbating in the process new areas of exclusion. This may have led to opportunities for some, but for the majority it has led to growing inequalities and disparities of economic wealth and violence is deeply embedded in the consequent increase of social and economic insecurity. have been made irrelevant to the interests of dominant economic and political power. Put differently, global and national patterns of consumption and production are threatening livelihoods and wellbeing causing discontent and conflict on an unprecedented scale.

Secondly, the dominant actors who give content to and 'do' development rarely acknowledge another process of violence - the disruption and destruction of the sources of life on our fragile planet - the lands, forests, air and water systems that we depend on. We are polluting and destroying the planet at an enormous and frightening rate through mining, deforestation, pesticide-intensive agriculture, the massive dumping of toxic wastes, dams, the unsustainable intensive extraction from our oceans, rivers, forests and lands. Take the much-heralded green revolution of the late 1960s and 1970s - for instance in the Indian states of Punjab and Haryana. New evidence suggests a widening of dying soils, the critical lowering of groundwater and its pollution by the leaching of pesticides and fertilizers.

We are now confronted with a situation where life itself is considered even more disposable or is being re-engineered to sustain the control of a few at the expense of the many. For instance, genetically modifying organisms is an insidious manipulation of life to sustain private profit without concern for ecological diversity and security or social justice. We have moved from extraction from nature and attempting to dominate it to privatizing and re-engineering it.

The multiple levels and growing intensity of violence should compel the development community to better understand and challenge the anthropocentric worldview that not only exploits, manipulates and engineers nature doing grave damage in the process but also does violence to the thousands of years of wisdom of communities who have lived with nature and who have evolved complex knowledge systems. It is imperative that the pluralities of knowledge systems that have evolved with nature rather than against it are brought to the centre of political, social and economic action.

We need urgently to transit to a biocentric perspective that recognizes that we are an integral 


\section{Kothari and Harcourt: The Violence of Development}

part of nature and must act accordingly. By using natural resources far beyond nature's regenerative capacity, by contributing to the daily extinction of species, we do violence to nature and to those whose livelihoods, which are dependent on nature, are threatened or destroyed by development. We are literally undermining the future of our own species. By appropriating the commons, a collective domain, and privatizing it, we are denying men and women their basic right to life. The developmental and political system that allows a private (often foreign) company to privatize water, a life source of all, reinforces inequality and excludes those who are unable to pay for this basic survival resource. Justifying privatization in the name of enhancing water and food security and in the name of development is a travesty.

Thirdly, in the same way that nature is grossly disrespected and violated, so too is culture. The world's cultural pluralism is being steadily, often violently, eroded with an alarming loss of ethnicities, knowledge systems, languages and traditional cultural forms of expression. There is a deep-seated violence that is severely threatening and ultimately destroying the identity and rights of ethnic and indigenous groups. There is a profound need to protect creative and grounded cultural, social and political pluralism and diversity through a deepening of the democratic process. The respect for plurality is a prerequisite to resist the subjugation of marginal groups and to resist homogenizing, developmental and scientific processes.

The evidence of how development has contributed to cultural homogenization is now all around us. In fact, as Arturo Escobar states in his essay in this issue, the inherent violence to marginalized people is written into development's birth certificate with its interdependent link with the dominant patterns of economic growth, technology and modernity. One example is the invasion of a global corporate-dominated media based on an inherent assumption of the superiority of one set of cultural and economic priorities with the implicit, if not explicit, inferiority of another. The spread of such global 'news' and representations of domestic and political life can be seen as a violent attack on the plurality of people's expressions, activities and lives. This cultural invasion leads to deep insecurities, which in turn breeds violence, intolerance, bigotry and prejudice against those groups who are perceived as 'the other'. Additionally, the sexualization of women and girls in this process, through promotion of certain forms of acceptable behaviour and appearance, pornography, even the fixation on rape and graphic scenes of violence against women in news reporting, lead in complex but disturbing ways to increased violence and oppression in the family, the home and in society at large. The resistance to this by women in many societies has been strong, but the trend of gender violence continues around the world, closely linked to other forms of economic and social violation.

Fourthly, the destabilization of natural systems and the threat to cultures and traditions and ensuing insecurities and violence is a problem not of poverty but rather the reverse. It is a problem of wealth creation. The privileging of materialism and the dominant patterns of achieving economic growth as the only road to development creates poverty, threatens and destroys livelihoods, creates mass insecurities, breaking down homes and communities, forcing men and women, often displaced from their familiar environment, into criminality. It is this criminalization of poverty that has led to some of the worst forms of gender violence as insecurities compound violence within the family as men are compelled to redefine their identities, both culturally and individually and endure life-threatening economic insecurities. The underbelly of the violence inherent in development is reflected in the heightened levels of domestic violence, the discrimination against the girl child, the increase of women entering the workforce in debilitating and unhealthy conditions, the trafficking of women and children, the increase in suicides and the spread of HIV/AIDS. All this while those doing development claim to be 'alleviating' poverty and 'listening' to the voices of those they label poor.

Moving from the community level to the geopolitical level, it is also important to look at the macro-context of violence that allows policymakers to pay little attention to the voices from the marginalized and the growing mass resis- 
tance to economic globalization. The process of national and global policymaking and today's geopolitics in the wake of September 11, the invasion of Iraq and the growing US hegemony is the enabling environment for so much violence to go unheeded in the name of freedom, democracy and development.

Fifthly, centralized administrative and policy processes contribute to the violence of development by imposing standardized, homogenizing solutions on plural cultural, social and economic contexts. The policy process has perpetuated a compartmentalized response to the complex, integrated realities that most people live in. So, for example, agriculture, water, energy and forests are different policy arenas with little or no coordination between them when in the life of a community dependent on natural resource systems, they are not just inter-related arenas but integrated systems. Compartmentalized policy responses inevitably fail to see many different elements that affect the lives and livelihoods of communities. How then can we speak of health when there is no access to clean water, of reproductive rights when there are no bathrooms, of democracy when livelihoods are not guaranteed, of participation when there is no education for women and of accountability when massive military and economic power is routinely used to subjugate peoples and nations?

Fundamentally, this is because the huge disparities that exist between the economic poor and the elites in our societies undermine the very concept of democratic governance. Those that have economic and political power dominate the representative process and through processes of democracy and in the name of development continue to perpetuate their own power and dominance, defending the economic, cultural, educational, social and political structures and systems that protect their interests at the expense of cultural pluralities, ecologies and diversities.

This hegemonic process articulates and thereby imposes the dominate pattern of development and democracy as the only relevant pattern and the only one to be followed, ignoring the huge represented and marginalized by the national and global governance systems. It is not surprising then that across much of the world, communities are redefining democracy whether by defying it, or deepening it, or by defending the community from its corrosive influence by asserting greater autonomy from it.

Violence, then, in its manifold manifestations is inherent in the current patterns of development. It cannot be dealt with by safety nets and superficial solutions, or by palliatives such as micro-credit schemes, capacity building workshops, etc. These development programmes and projects, however well designed, fail to address the causes of the violence, the destruction of nature and culture and of plural ways of knowing, being and doing, the inadequacies of the dominant democratic process, the inequality of access to resources and spaces for expression. Across the world, local communities, urban and rural groups and social movements are emerging at thousands of sites to respond to the manifold violence that they experience. From Chiapas in southern Mexico to the valleys of the Narmada river in India, from the World Social Forum to the United Nations Forum on Indigenous Peoples, their representatives are highlighting this violence and exclusion, and asserting their own way of being in the face of the homogenization, standardization and violence in their daily lives.

While acknowledging, even celebrating the innovation and strength of these movements, it is important not to instrumentalize them, presuming to select and appropriate from their experience and knowledge in order to improve other lives. Instead, we need to recognize the lessons they highlight and the numerous possibilities they open up, recognizing also that in the face of dominant economic and political power, they remain fragile and vulnerable. Often they are responses to desperate needs. It is important to work collectively together, to form creative alliances and networks respecting the many different needs and therefore ways of organizing livelihoods, production systems and social structures to create more secure and culturally richer lives, and above all in harmony with this fragile planet, our only home. 


\section{Kothari and Harcourt: The Violence of Development}

In this last goal, we have to recognize that it is important not only to support the pluralities of living but also to challenge the primacy we have given to materialism over all other forms of human action and expression. The dominant and dominating pursuit of material wealth has negated more comprehensive value systems.
As the articles in this issue demonstrate so clearly, the challenge is not to regulate and reform development and the pursuit of economic growth, but to transform them so that we can all live in harmony and justice with the richness and diversities of all cultural and life forms. 